\title{
Labour market under economy digitalization
}

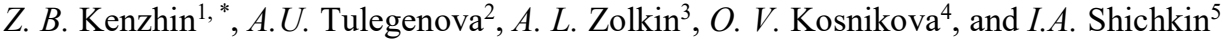 \\ ${ }^{1}$ West Kazakhstan agrarian and technical University named after Zhangir Khan, Uralsk, Kazakhstan \\ ${ }^{2}$ West Kazakhstan Innovative and Technological university, Uralsk, Kazakhstan \\ ${ }^{3}$ Povolzhskiy State University of Telecommunications and Informatics, Samara, Russia \\ ${ }^{4}$ Kuban State Agrarian University named after I.T. Trubilin», Krasnodar, Russia \\ ${ }^{5}$ Plekhanov Russian University of Economics, Moscow, Russia
}

\begin{abstract}
The main problems of current labour market under economy digitalization caused by COVID-19 pandemic are reviewed in this article. Current economy system is based on factors of innovative development that effects on labour market and, therewith, reducing employment of population and increasing of structural unemployment. Therefore, the problems of labour market studies are becoming actual according to structural development of economy system itself in the age of economy globalization. Methodological framework has defined against the background of developed procedures and regulatory settings for regulation of labour market and labour power in Kazakhstan. The assessment, composition and statistical analysis methods were used for studies.
\end{abstract}

\section{Introduction}

Economy and political events of modern world have strong effect on labour marker in Kazakhstan. The events happening inside country as well as outside events are important.

Full employment of population facilitates the development of economic as main factor of labour capacity for increasing and growing of mobile labour power. Moreover, emerging the new technologies stimulates the economy development; however, their emerging favours in change of social and economic relations including the economic, labour market, business environment and so on.

Apparently, the technologies directly effect on labour market that was significantly changed over the past two decades: some professions passed away due to the lack of their necessity, other became highly wanted, and the new ones were developed. Intensive development of digital, global enter of such leading global companies as Google or Apple in life of society, noticed upheavals in global economic led to significant changes of labour market [1]. Therefore, each country tries to regulate the process and guarantee the employment of population by increasing of government expenditures (transfer payments). This event is temporary and associated with trends of economy cycles but requires the specific measures on labour market regulation.

\footnotetext{
*Corresponding author: jaksat_22@mail.ru
} 


\section{Problem statement}

According to Atlas of professions, the processes of production systems are changed; at the same time innovations and informative and communicative technologies strongly effect on labour market. The labour power becomes unclaimed and there is no demand on specific specializations, there is a change of new professions that require taking into account the requirements of employers and guarantee the opportunity to get a job under the National Qualifications Framework, which was developed according to the European Qualifications Framework; this approach made it possible to recognize Kazakhstan's education ( diploma) in the European labour market. Therefore, there is a need of labour mobility and its demand on global labour market but this lead to brain drain abroad that makes this study is actual.

\section{Research questions}

Labour market is economy relation system whereby exchange of labour services on material or other profits takes place. Labour market has a set of features. This is not only purchase and sale area or labour exchange but this is labour potential reproduction and labour service area $[2,3]$. Supply and demand on labour market depends on various factors. At the moment high innovative and technical infrastructure, digitization and automation are the main factors that lead to reducing the demand on labour. However, it might to be considered that reducing of demand on labour takes place in areas with automation and digitization of labour but the demand on labour is increased in areas where new equipment and its maintenance are produced.

\section{Materials and methods}

Methodological framework has defined against the background of developed procedures and regulatory settings for regulation of labour market and labour power in Kazakhstan. The assessment, composition and statistical analysis methods were used for this study.

\section{Results}

According to the UN's forecasts, the global population will be increased from current 7.5 billion of individuals to 8.5 billion by the year 2030. The number of people in Kazakhstan will reach 24 million against 18.6 million in 2019. Projecting the current level of economy activity on the advanced mass of our country population, taking into account the rate of increase of life expectancy and retiring age, the part of our economy active people abroad will exceed at the turn of 2030 - 14.4 millions of working age people against 9.2 million [4].

For modern Kazakhstan is important to study the labour market of foreign countries and specially those the economy of which as well as demographic situation are similar to Kazakhstan ones. Moreover, the experience of countries reel from major reconstruction in economic including innovation, re-thinking of ideological and moral values, changes in social policy, and implementation process of digital technology in business's activities has value.

The results of labour market problem studies show that many home manufacturers are still not available for automation and digitization of business's activities. At the same time regarding the implementation of new innovative technologies on enterprises the labour power faces with multiple issues, particularly, would it be the creation of new working 
places on market or significant their reducing available in different economy areas and what is important source of structural unemployment. However, in Klaus Martin Schwab's opinion some countries with developing economics are actually eliminated from process of development of new technologies and knowledge effect on their societies, and not effected by new industrial revolution. As countries with developed economics are first movers of scientific and technical progress the balance between technologies, society and economics can be easily shifted to their side. Without any activities, the future for developing countries will be developed in random ways not targeted, and technologies will limit the opportunities but not expand $[5,6]$.

\section{Findings}

The unemployment is specific feature for market system and inevitable one when some specializations will be unclaimed. Under innovative development numerous small, middle and large-scale enterprises contributes to new technology's implementation resulting many workers are leaving out of enterprises. However, the labour power in construction field is still in-demand regards the development of this field in Kazakhstan. The re-qualification and re-training of labour power taking into account the structural changes in economic will be needed due to the demand on other specializations.

The main challenges of unemployment in Republic are connected not only with availability of free vacancies but, first of all, with skilled labour power shortage. The assessment of industrial enterprise's activity shown that many of them do not have the labourpower with appropriate skill level. At the same time, there are too much individuals with unclaimed professions where the competition for working place is very high. The results of assessment shown that only in 2019142.4 thousands of specialists were graduated that is higher on $9 \%$ against 2018 . However, from the side of quality manpower preparation this parameter requires the re-assessment of their qualification and skill level according to employer's requirements as in the employer's opinion the graduates do not have the sufficient practical skills and the employers are not ready to employ and guarantee them the high salary.

The unemployment level for 2020 is $5 \%$ against $4.8 \%$ in 2019 . According to data of Ministry of National economic of Kazakhstan Republic, the level of unemployed men and women was 216.3 thousands and 237.7 thousands people respectively [7]. At the same time, the highest unemployment level in 2020 was $13.7 \%$, and the lowest level was up to $4.8 \%$ (see Fig.1). These values provide evidence that social and economy costs of unemployment are growing.

In the second quarter of 2020, there were 454 thousands of unemployed individuals that is on $2.8 \%$ higher than in the second quarter of 2019 . The number of unemployed men and women was 216.3 thousands and 237.7 thousands individuals respectively. The unemployment level for men and women was $4.6 \%$ and $5.4 \%$ respectively.

If analyse the unemployment level with regards to town and country it is lower for country (174.7 thousands individuals with unemployment level 4.7\%) than for town $(279.2$ thousands individuals with unemployment level 5.1\%). 


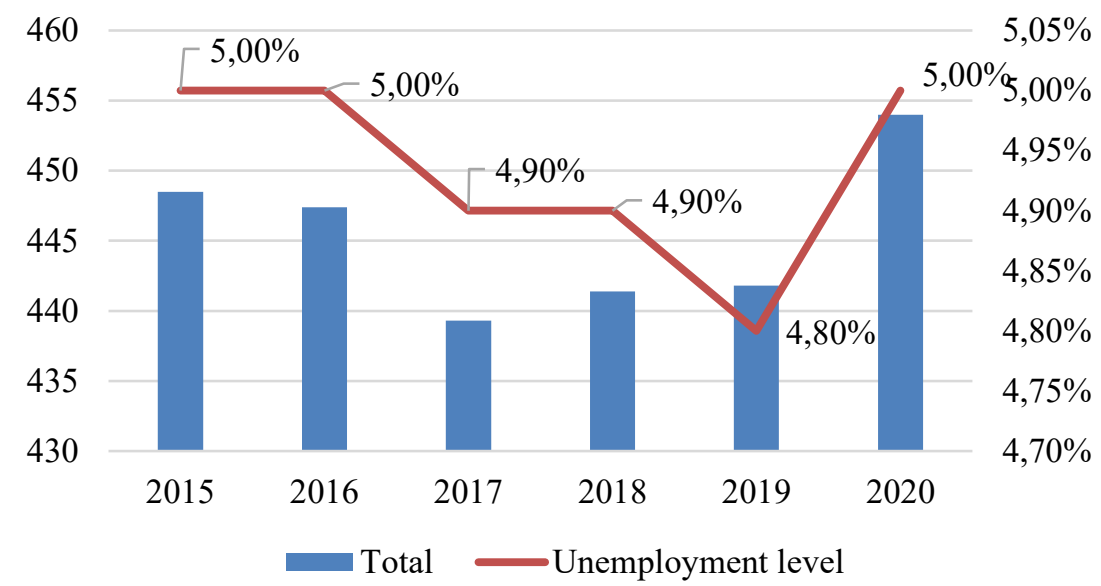

Fig. 1. Unemployment level in Kazakhstan Republic.

Regionally the highest quantity of unemployed people was in south areas of country: Almaty, Almaty and Turkestan regions.

There are 54 thousands of unemployed individuals in Almaty that is $7.3 \%$ higher than for last year. 49.4 thousands of unemployed individuals live in Almaty region that is plus $3 \%$ over year; 42.3 thousands of unemployed individuals live in Turkestan region that is plus $0.6 \%$ over year.

\section{Discussion}

Due to the COVID-19 pandemic in 2019, the global labour market was hit hard as well as economic totally. Early April 20203.3 billion people or $81 \%$ from total working power suffered from complete or partial job cut. March-April, 2020 in Kazakhstan, specifically, 4.4 million of people stayed temporary unemployed due to the quarantine measures. Totally, as on January 1st, 2021 the unemployment level in country was 5.1\% or 457600 unemployed people because of negative effect of crisis.

To solve the problem on Kazakhstan labour marker as well as on foreign countries the stimulus measures are intensified for the purpose to assure the complete population employment.

Measures to control the unemployment include the set of social guarantees, social insurance, various forms and methods of social support from unemployment specifically two main social groups - working people who are upon pain of dismission, and unemployed people registered in state employment service [8].

"Action plan for employment" implementation in Kazakhstan favours to solve the problem of social and economic costs of unemployment. Within the action plan, more than 6.5 thousand projects were presented, in which 255 thousand working places were created. A special condition for implementation of "Action plan for employment" infrastructure projects is to ensure the use of at least $90 \%$ of goods and services of domestic manufactures; in addition, at least $50 \%$ of workers will be hired through employment services. As on July 15, 2019, work on 6295 projects began in the regions, more than 148 thousand working places created, including 77 thousand ones through employment services.

The Employment Services (hereinafter the Services), which function in all regions of the country, remains one of the most important mechanism for labour market regulation. 
The Service's activity is addressed at analysis and forecasting the supply and demand for labour power, their employment, re-training and re-qualification, etc.

The services are a mechanism for employment and labour market management, what effects on the indicator of social and economy development of country. It should be noted that the management of processes taking place in the labour market in foreign countries is based on the principles of social partnership. The "social partnership" concept is used in the West mainly by social democrats. Historically, it has opposed to class struggle. Now, the confrontation between labour and capital has not become so acute due to the general rise of the living level of the population of countries with market systems. The middle class in these countries is $70-80 \%$ of the population. In such conditions, the slogans of social partnership began to be used to political stability strengthening in the country $[9,10]$.

The analysis of Service's activity shown that according to the results of the first quarter of 2020, more than 3.3 thousand people were employed for permanent work, while the largest number of labour power (651 people) were employed through the employment services of Nur-Sultan city. It should be noted that such difference in the number of employed people is according to a demographic factor, namely the uneven distribution of the country population, what is very actually for Kazakhstan. Therefore, there is a lack of demand in some regions and glut in others. Commonly, salaries in all regions for the same professions are different; the average monthly salaries of Kazakhstan population in the fourth quarter of 2020 were 203.9 thousand tenge, what is $15.8 \%$ more than in the same period in 2019. Taking into account the inflation, the real growth of salary purchasing power was a significant $9.9 \%$. However, the lack of demand on labour power in specific regions is a positive side of the labour market, it makes possible of labour power mobility and find the prospects for them in other regions, and is a disadvantage for mature people or citizens of pre-retirement age who have been laid off. Therefore, development of social legislation is needed: the setting of subsistence level, unemployment payments, pension payments, the development of health care, etc.

Modern labour market management has become more multi-faceted and systemic, at the same time trend of educational and innovative development pick up is important, what will help to increase the necessary skills and ensure the functioning of the labour market, taking into account the technological revolution. Such factors effects on the skills of labour power and the ability to achieve them. This requires labour power and companies to adapt to changing conditions and culture, as well as to meet the expectations of a new generation of candidates and employers. At the same time, employment trends are constantly changing, therefore employers and the labour power must adapt to the transformation of the labour market in order to be well informed of changing trends in this area.

\section{Conclusion}

Hereby, the fourth industrial revolution has a powerful effect on the restructuring of the labour market in Kazakhstan. These processes strongly effect and present in all fields of the economy, since it is a subject to various natural, technological, social and economic and political factors. It is difficult to overestimate the importance of economy fields, but at the same time, their dependence on various external factors is also very high.

Three main factors effect on labour market of the country from social and technological sides: the emergence of a new labour power (economically active), increase in the duration of the active labour power's presence in the market, and technological re-equipment, that frees up the labour force. The last two factors hold down the possibilities of the labour market for stable growth, and the first one, which is key from a social and political point of view, needs it. If ignored, this situation will eventually reach a phase when the labour market will not be able to absorb the ever-increasing flow of new employees. 
New technologies lead to transformation of the labour market on an unprecedented scale. Professions disappear and change, new specializations appear. Corporations, governments and economy industries compete for the intellectual capital of the future people with skills and competencies focused on the economy with innovative development. In Kazakhstan, the implementation of "Action plan for employment" determines the state policy in the field of population employment regulation, that ensures the reducing of social costs of unemployment in the country.

\section{References}

1. D.-J. Rahmil, How is digital technology changing the labour market? (2014)

2. E. G. Yakovenko, Labour economic, 320 (2012)

3. A. A. Kochetkov, Economy theory: Bookfor bachelors, 696 (2013)

4. K. Grass, E. Weber, The Debateon Digitalisation and the Labor Market in Europe (2016)

5. F. Delfani, H. Samanipour, H. Beiki, A. Yumashev, E. Akhmetshin, Int. J. of Systems Science: Operations and Logistics, 1 (2020)

6. M. A. Chirkov, T. A. Lachinina, M. S. Chistyakov, Free Thought, 37 (2020)

7. E. Lavrov, Eastern-European J. ofEnterprise Technologies, 2(86), 4 (2017)

8. E. A. Lavrov, P. I. Paderno, A. A. Volosiuk, N. B. Pasko, V. I. Kyzenko, Proceedings of 2019 3rd Int. Conf. on Control in Technical Systems, CTS 2019, 144 (2019)

9. I. A. Poskryakov, V. D. Munister, A. L. Zolkin, M. A. Kuzmin, N. F. Zavialova, IOP Conf. Series. Krasnoyarsk Science and Technology City Hall, 32014 (2021)

10. A. L. Zolkin, T. G. Aygumov, A. I. Pakhomova, V. V. Bobkov, IOP Conf. Series: Earth and Environmental Science. Krasnoyarsk Science and Technology City Hall. $22032(2021)$ 